\title{
Transformation of peptide nanotubes into a vesicle via fusion driven by stereo-complex formation.
}

\section{$\operatorname{AUTHOR}(\mathrm{S}):$}

Ueda, Motoki; Makino, Akira; Imai, Tomoya; Sugiyama, Junji; Kimura, Shunsaku

\section{CITATION:}

Ueda, Motoki ... [et al]. Transformation of peptide nanotubes into a vesicle via fusion driven by stereo-complex formation.. Chemical communications 2011, 47(11): 3204-3206

\section{ISSUE DATE:}

2011-03

URL:

http://hdl.handle.net/2433/156523

\section{RIGHT:}

(C) The Royal Society of Chemistry 2011.; This is not the published version. Please cite only the published version.; この論文は出版社版で ありません。引用の際には出版社版をご確認ご利用ください。 


\title{
Transformation of Peptide Nanotubes to Vesicle via Fusion Driven by Stereo-complex Formation
}

\author{
Motoki Ueda, ${ }^{a}$ Akira Makino, ${ }^{a}$ Tomoya Imai, ${ }^{b}$ Junji Sugiyama, ${ }^{b}$ and Shunsaku Kimura* ${ }^{a}$ \\ Receipt/Acceptance Data [DO NOT ALTER/DELETE THIS TEXT] \\ Publication data [DO NOT ALTER/DELETE THIS TEXT] \\ DOI: 10.1039/b000000x [DO NOT ALTER/DELETE THIS TEXT]
}

Two types of peptide nanotubes, one is prepared from an amphiphilic peptide having a right-handed helix segment and the other from that having a left-handed helix segment, are shown to 10 transform the morphology to vesicle by membrane fusion due to stereocomplex formation between these chiral helical segments.

Helical peptides are easily designed to take either helicity, righthanded or left-handed, by using L- or D-residues in the sequence. When the right-handed helix is mixed with the left-handed helix, 15 they are expected to form a stereo-complex probably due to the convexo-concave fitness between their surfaces. With using stereo-complex formation of these helical peptides, we demonstrate here vesicle formation from two types of peptide nanotubes by membrane fusion.

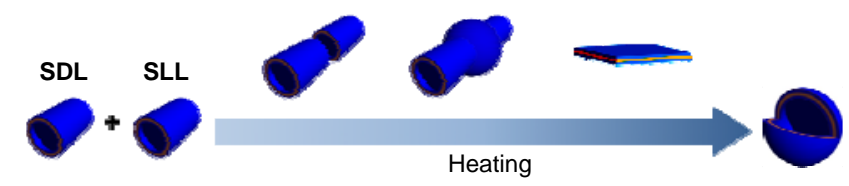

等

20 Several morphologies in the shapes of micelle, rod-shaped micelle, sheet, tube and vesicle have been prepared in solution by the current self-assembling techniques. ${ }^{1-4}$ We have reported on molecular assemblies of amphiphilic peptide molecules especially with using hydrophobic helical peptides at the hydrophobic core 25 of the molecular assemblies. ${ }^{5-9}$ Helical peptides have a good ability to be packed regularly in the molecular assembly as shown by frequent observation of helix bundles in nature. ${ }^{10,11}$ Indeed, several hydrophobic helical peptides with attachment of suitable hydrophilic groups formed vesicular assemblies with a diameter 30 of ca. $100 \mathrm{~nm}$ in water, which are named "peptosome". ${ }^{8}$ Further, peptide nanotube with diameter of ca. $60 \mathrm{~nm}$ and length of ca. $200 \mathrm{~nm}$ was obtained from amphiphilic block polypeptide with a hydrophobic helix, $(\mathrm{Sar})_{27}-b$-(L-Leu-Aib) ${ }_{6} \cdot{ }^{12}$ In the latter case, the block polypeptide initially formed a curved square sheet 35 assembly, which was transformed quantitatively to nanotube morphology upon heating at $90{ }^{\circ} \mathrm{C}$ for $10 \mathrm{~min}$. The transformation mechanism from the curved sheet to the nanotube

\footnotetext{
${ }^{a}$ Department of Material Chemistry, Graduate School of Engineering, KyotoUniversity, Kyoto-Daigaku-Katsura, Nishikyo-ku, Kyoto 615-8510. E-mail: shun@scl.kyoto-u.ac.jp; Tel: +81-75-383-2400, Fax: +81-75383-2401. ${ }^{b}$ Resarch Institute for Sustainable Humanoshpere, Kyoto University, Gokasho, Uji, Kyoto 611-0011

Elecronic supplementary information (ESI) available: Experimental details of synthesis and characterization. MALDI-TOF/MS spectra of the peptides. CD spectra. AFM image of $\mathbf{1}$.
}

is just to stick two opposing hydrophobic sides of the square sheet, which is unique from other reports on nanotube formation, 40 where twisted long sheet or helix ribbon generally fused the edges together to grow into nanotubes. ${ }^{13-17}$ On the other hand, in our nanotubes, the size of the nanotube is determined by the initial size of the curved square sheet, which has an advantage of a very narrow size distribution of the produced nanotubes. The 45 reason for the sheet curving is considered to be due to the regular packing of the right-handed helices in the hydrophobic core, similarly to the recent studies on molecular assemblies with chiral molecules. $^{18-31}$

Poly(sarcosine) is used here as a hydrophilic segment, 50 because it is as hydrophilic as poly(ethylene glycol), and sarcosine is biodegradable by endogenous sarcosine dehydrogenase. We have applied the amphiphilic peptide micelles made of $(\mathrm{Sar})_{\mathrm{n}}-b-(\mathrm{Glu}-\mathrm{OMe})_{\mathrm{m}}{ }^{5}$ or $(\mathrm{Sar})_{\mathrm{n}}-b$-(lactide $)_{\mathrm{m}}{ }^{6}$ for in vivo tumor imaging with using near-infrared fluorescence ${ }_{55}$ labelling probe. These poly(sarcosine) conjugates are shown to be highly biocompatible. The (Sar) ${ }_{25}$ block is here attached to the $N$ terminal of the hydrophobic helical block, (L- or D-Leu-Aib) ${ }_{6}$, via polymerization of sarcosine $\mathrm{N}$-carboxy anhydride (NCA) to obtain SLL or SDL (syntheses and identification in supporting 60 information (SI)).

Morphologies of molecular assemblies are studied by transmission electron microscope (TEM) with negative staining or cryogenic freezing. As previously reported, SLL as injected in buffer takes a homogeneous nano curved-sheet morphology. ${ }^{12}$ ${ }_{65}$ The same nano curved-sheet assembly is also obtained from SDL. These nano curved-sheet assemblies are transformed to nanotubes by heating the molecular assembly solution at $90{ }^{\circ} \mathrm{C}$ for $10 \mathrm{~min}$. Circular dichroism (CD) measurements show that SLL and SDL in the molecular assemblies take right-handed and left-handed $\alpha$ 70 helix, respectively. Further, the Cotton effect at $222 \mathrm{~nm}$ is slightly stronger than that at $208 \mathrm{~nm}$, indicating that the helices form a tightly packed bundle structure (Fig. S2 in SI).

The important point of these nano curved-sheet and nanotube is that they are metastable, where upon heating transformation 75 from the nanosheet to the nanotube occurs quantitatively, and upon further heating elongation of nanotube to double and triple was observed. ${ }^{12}$ Even though the hydrophobic edges of the nanosheet and the nanotube are stabilized by a shielding effect of poly(sarcosine) chains nearby, the edges can be fused with other so hydrophobic surfaces upon heating.

Nanotubes are prepared separately from SLL and SDL, and two types of the nanotubes are mixed at an equimolar ratio. The mixture is heated at $90{ }^{\circ} \mathrm{C}$ for $50 \mathrm{~min}$, and the time course of morphology change is analyzed by TEM (Figures 1A-D). Before ${ }_{85}$ heat treatment, nanotubes with diameter of ca. $60 \mathrm{~nm}$ and length 


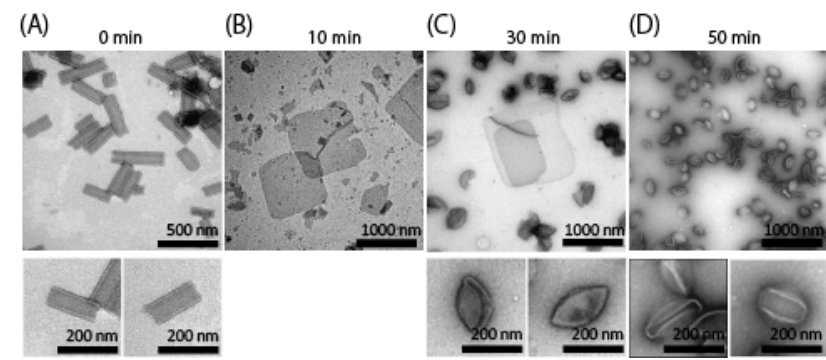

Fig. 1 The TEM images of the mixture of assembly suspension from SLL and SDI upon heating at $90{ }^{\circ} \mathrm{C}$. The each assemblies were prepared in $10 \mathrm{mM}$ Tris- $\mathrm{HCl}$ Buffer (pH 7.4) (3 mg / $1 \mathrm{~mL})$ by the ethanol injection method.
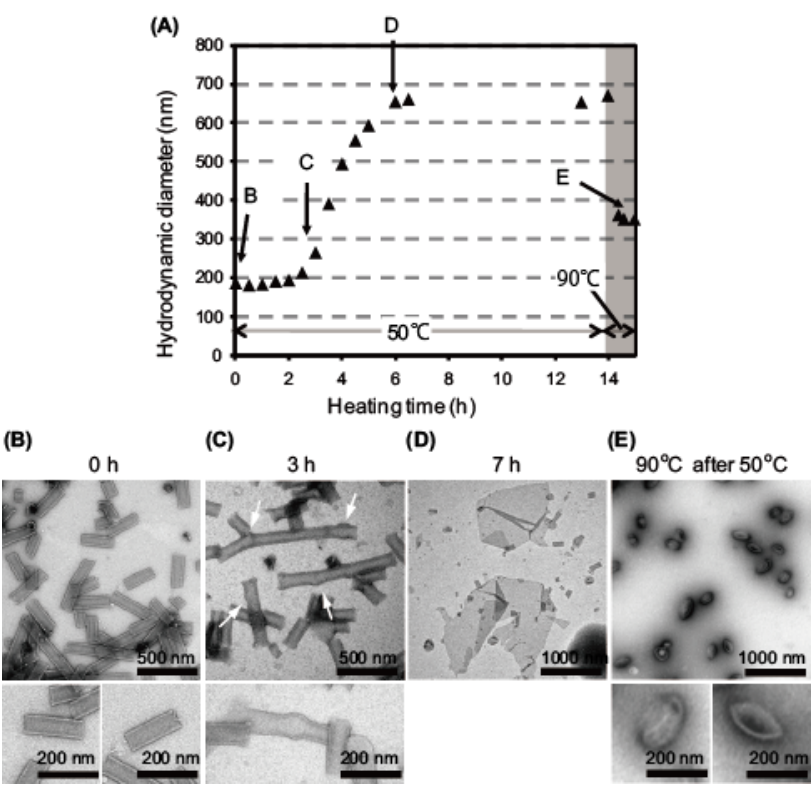

Fig. 2 The DLS data (A) and TEM images (B-D) of the mixture suspension upon heating at $50{ }^{\circ} \mathrm{C}$. (E) The TEM images of same sample upon heating at $90{ }^{\circ} \mathrm{C}$ for $1 \mathrm{~h}$ after heaing at $50{ }^{\circ} \mathrm{C}$ for $14 \mathrm{~h}$

of ca. $200 \mathrm{~nm}$ are homogeneously formed (Figure 1A). Upon heating for $10 \mathrm{~min}$, planar square sheets with ca. $1 \mu \mathrm{m}$ side appear in TEM image (Figure 1B). Then, the sheets are gradually transformed to vesicles (Figures 1C and 1D). Transformation of 90 the sheet to the vesicle is completed within $50 \mathrm{~min}$ at $90^{\circ} \mathrm{C}$. With SLL or SDL alone, no such change was observed but just elongation of the nanotubes partially. It is thus speculated that the SLL nanotube and the SDL nanotube should fuse together to transform the nanotube morphology to the planar square sheet.

${ }_{95}$ Indeed, the observation of a planar sheet can be reasonably explained by mixing of enantiomeric polypeptides SLL and SDL with stereo-complex formation to generate the achiral planar sheet. Whereas, SLL or SDL alone forms the curved sheet due to the one-handed helix association with a regular tilt angle between 100 the helices. To investigate the morphology transformation mechanism in detail, the same fusion system is examined at lower temperature as follows.

Upon heating at $50{ }^{\circ} \mathrm{C}$, the peptide nanotube fusion process proceeds slowly compared with that at $90{ }^{\circ} \mathrm{C}$. TEM observations 105 reveal that upon heating at $50{ }^{\circ} \mathrm{C}$ for the initial $1-2 \mathrm{~h}$, longer nanotube assemblies connecting two or more tubes are observed (Figure 2C). Hydrophobic edges at the open mouths of the nanotubes therefore trigger the association of the nanotubes. Interestingly, some bunchy connecting regions of two nanotubes 110 are observed (Figure 2C and S3 in SI). This observation strongly
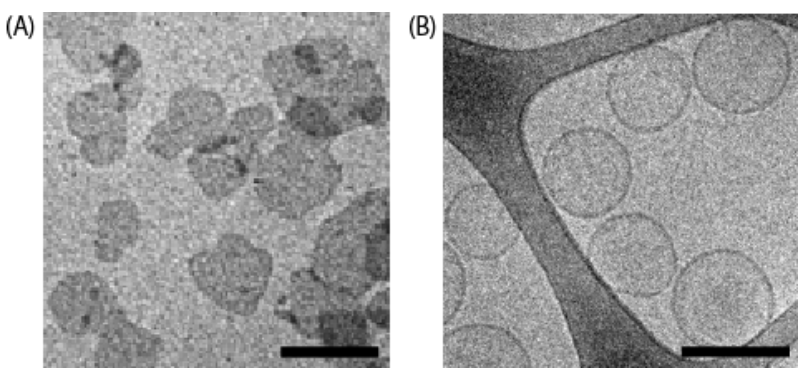

Fig. 3 TEM images (negative staining with uranyl acetate; A, cryogenic TEM; B) of molecular assemblies from mixtures of helical polypeptides SLL and SDL; 50/50. The assemblies were prepared in $10 \mathrm{mM}$ Tris- $\mathrm{HCl}$ Buffer $(\mathrm{pH} 7.4)(3 \mathrm{mg} / 1 \mathrm{~mL})$ by the ethanol injection method. Before heat treatment; (A), and after heat treatment; (B). The scale bars are $500 \mathrm{~nm}$ for (A), and $200 \mathrm{~nm}$ for (B).
(A)

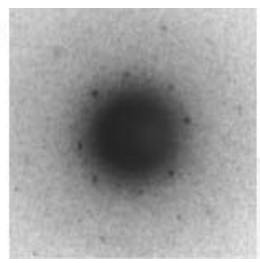

(B)

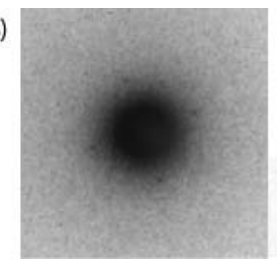

Fig. 4 TEM images and electron diffraction patterns of (A) the planar sheet assembly from an equimolar mixture of SLL and SDL and (B) the nanotube assembly from a single component of SDL in $10 \mathrm{mM}$ Tris- $\mathrm{HCl}$ buffer ( $\mathrm{pH}$ 7.4).

indicates the mixing of SLL and SDL takes place to generate a vesicle-like morphology at this connecting region. After heating for $7 \mathrm{~h}$ at $50{ }^{\circ} \mathrm{C}$, the fused nanotubes are broken up and transformed to a planar square sheet with ca. $1.5 \mu \mathrm{m}$ side (Figure $1152 \mathrm{D}$ ). These results indicate that the polypeptide nanotubes are connected randomly at the initial stage (association). When two types of the peptide nanotubes are connected, the right- and the left-handed helices diffuse through the connecting moieties to induce membrane fusion, because the stereo-complex is 120 thermodynamically stable. ${ }^{14}$ The mixing proceeds with time, and finally the tubular structure breaks up to take the planar square sheet. It takes more than $7 \mathrm{~h}$ to form the planar sheet (Figures 2D). Upon heating at $90^{\circ} \mathrm{C}$, transformation to vesicle is attained. The morphology changes are followed by DLS similarly as changes ${ }_{125}$ of hydrodynamic diameters (Figure 2A). Importantly no vesicular assembly transformation from the planar sheet was observed at $50{ }^{\circ} \mathrm{C}$, suggesting that the transformation from the planar sheet to the vesicle requires higher energy.

We confirm the vesicle formation due to the stereo-complex 130 formation by using another preparative method. An equimolar mixture of SLL and SDL in ethanol is injected into a buffer solution. The morphology of the self-assembly is a planar-sheet (Figure 3A), which is different from the curved sheet prepared from the single component. Further, upon heating at $90{ }^{\circ} \mathrm{C}$ for $1 \mathrm{~h}$, 135 vesicles are quantitatively formed (Figure 3B, cryo-TEM). The size distribution of the vesicles is very narrow around $200 \mathrm{~nm}$ diameter. Since this size is smaller than the expected size by closing the planar sheet with $1.5 \mu \mathrm{m}$ side, the planar sheet should be torn off to generate the most stable size of the vesicle. This 140 should be the reason for the narrow distribution of the vesicle diameter.

We have shown two different preparation methods for the same vesicle morphology, which confirms our interpretation of vesicle formation due to the mixing of the right- and the left145 handed helices in the molecular assembly, which is 
thermodynamically induced by the stereo-complex formation. Indeed, electron diffraction pattern and FTIR spectrum from the vesicle are different from those of the nanotube, indicating tight molecular packing of SLL and SDL in the vesicle due to the 150 stereo-complex formation (Figure 4, S4 and S5).

In conclusion, we demonstrate a new method for vesicle preparation by a novel fusion mechanism, which is driven by the stereo-complex formation of the helical amphiphiles. Morphology transformation process from the nanotube to the 155 vesicle is composed of four steps; i) nanotube association, ii) mixing of right- and left-handed helices, iii) break-up of the tubular structure to the planar sheet structure, and iv) closing to the vesicular structure. This fusion mechanism will pave the way to construct more complex morphologies which is now under 160 investigation.

Acknowledgments. This study is a part of joint research, which is focusing on the development of the basis of technology for establishing COE for nanomedicine, carried out through Kyoto City Collaboration of Regional Entities for Advancing Technology ${ }_{165}$ Excellence (CREATE) assigned by Japan Science and Technology Agency (JST)

\section{Notes and references}

170

1 D. E. Discher, A. Eisenberg, Science 2002, 297, 967.

2 P. Jonkheijm, P. V. D. Schoot, A. P. H. J. Schenning, E. W. Meijer Science 2006, 313, 80.

3 H. Engelkamp, S. Middelbeek, R. J. M. Nolte, Science 1999, 284, $175 \quad 785$

4 V. Percec, A. E. Dulcey, V. S. K. Balagurusamy, Y. Miura, J. Smidrkal, M. Peterca, S. Nummelin, U. Edlund, S. D. Hudson, P. A. Heiney, H. Duan, S. N. Magonov, S. A. Vinogradov, Nature 2004, 430, 764

1805 H. Tanisaka, S. Kizaka-Kondoh, A. Makino, S. Tanaka, M. Hiraoka, S. Kimura, Bioconj. Chem. 2008, 19, 109.

6 A. Makino, S. Kizaka-Kondoh, R. Yamahara, I, Hara, T. Kanzaki, E. Ozaki, M. Hiraoka, S. Kimura, Biomaterials 2009, 30, 5156.

$7 \quad$ K. Fujita, S. Kimura, Y. Imanishi, Langmuir 1999, 15, 4377.

1858 S. Kimura, Do-Hyung Kim, J. Sugiyama, Y. Imanishi Langmuir 1999, 15, 4461

9 S. Kimura, Y. Muraji, J. Sugiyama, K. Fujita, Y. Imanishi, J. Colloid Interface Sci. 2000, 222, 265.

10 M. V. Milburn, G. G. Prove, D. L. Milligan, W. G. Scott, J. Yeh,

190 J.Jancarik, D. E. Koshland, S.-H. Kim Science 1991, 254, 1342.

11 M. W. Parker, F. Pattus, A. D. Tucker, D. Tsernoglou Nature 1989, 337, 93.

12 T. Kanzaki, Y. Horikawa, A. Makino, J. Sugiyama, S. Kimura Macromol. Biosci. 2008, 8, 1026.

19513 J. H. Fuhrhop, P. Schnieder, E. Boekema, W. Helfrich, J. Am. Chem. Soc. 1988, 110, 2861.

14 T. Kunitake, Angew. Chem. Int. Ed. 1992, 31, 709.

15 W. Yang, E. Lee, M. Lee, J. Am. Chem. Soc. 2006, 128, 3484

16 H. Yui, H. Minamikawa, R. Danev, K. Nagayama, S. Kamiya, T.

$200 \quad$ Shimizu, Langmuir 2008, 24, 709.

17 E. Pouget, N. Fay, E. Dujardin, N. Jamin, P. Berthault, L. Perrin, A. Pandit, T. Rose, C. Valéry, D. Thomas, M. Paternostre, F. Artzner, J. Am. Chem. Soc. 2010, 132, 4230.

18 Ou-Yang Zhong-can, Phys. Rev. A 1991, 43, 6826.

20519 J. M. Schnur, Science 1993, 262, 1669.

20 J. V. Selinger, Phys. Rev. E 1996, 53, 3804.
21 M. S. Spector, J. V. Selinger, A. Singh, J. M. Rodriguez, R. R. Price, J. M. Schnur, Langmuir 1998, 14, 3493.

22 R. Oda, I. Huc, M. Schmutz, S. J. Candau, F. C. MacKintosh, Nature 1999, 399, 566.

23 J. J. L. M. Cornelissen, A. E. Rowan, R. J. M. Nolte, N. A. J. M. Sommerdijk, Chem. Rev. 2001, 101, 4039.

24 J. V. Selinger, M. S. Spector, J. M. Schnur, J. Phys. Chem. B 2001, 105, 7157.

21525 J. P. Hill, W. Jin, A. Kosaka, T. Fukushima, H. Ichihara, T. Shimomura, K. Ito, T. Hashizume, N. Ishii, T. Aida, Science 2004, 304, 1481.

26 W. Jin, T. Fukushima, M. Niki, A. Kosaka, N. Ishii, T. Aida, Proc. Natl. Acad. Sci. USA 2005, 102, 10801.

22027 T. Shimizu, M. Masuda, H. Minamikawa, Chem. Rev. 2005, 105, 1401.

28 Y. Yamamoto, T. Fukushima, Y. Suna, N. Ishii, A. Saeki, S. Seki, S. Tagawa, M. Taniguchi, T. Kawai, T. Aida, Science 2006, 314, 1761.

22529 J. Ryu, H. Kim, Z. Huang, E. Lee, M. Lee, Angew. Chem. Int. Ed. 2006, 45, 5304.

30 A. Brizard, C. Aime, T. Labrot, I. Huc, D. Berthier, F. Artzner, B. Desbat, R. Oda, J. Am. Chem. Soc. 2007, 129, 3754.

31 J. Kim, E. Lee, M. Kim, E. Sim, M. Lee, J. Am. Chem. Soc. 2009, $230 \quad$ 131, 17768 